\title{
CONTRAMARCAS Y SELLOS DE LA LEGIO $X$ EN HISPANIA Y EN MOESIA O RENANIA
}

\author{
POR
}

\author{
M. ${ }^{a}$ PAZ GARCÍA-BELLIDO y EMANUEL PETAC \\ CSIC, Madrid y Biblioteca Academici Romene, Bucarest *
}

\section{RESUMEN}

Se publican piezas contramarcadas con «X», posiblemente el sello de la legión X Gémina, halladas en España y en Rumania. Se hace un estudio general sobre los resellos y contramarcas de esta legión conocidos sobre lingotes de plomo o monedas, constatándose el comienzo del habito legionario de resellar con su nombre ya en el año 19 a.C, durante la estancia de Agripa en Hispania. Las contramarcas monetales indican la presencia de la legión en Pannonia, Moesia o limes renano, en la Bética, en valle del Ebro y Petavonium (Zamora).

\section{RESUME}

A group of objects from Spain and Romania bear the mark «X», a device probably to be associated with legio $X$ Gemina. A survey of this legion's known stamps and countermarks on lead pigs and coins suggests that the practice began during Agrippa's tour of Hispania in 19 BC. Countermarked coins attest to the presence of the legion in Pannonia, Moesia or the Rhine fronter, as well as in Baetica, the Ebro valley, and Petavonium (Zamora).

Las contramarcas monetales con los nombres, símbolos o números de las legiones están cobrando recientemente especial importancia para perfilar la historia de ciertos cuerpos militares. La acumulación de estas contramarcas legionarias en ciertas zonas y en períodos de tiempo específicos, permite atestiguar la presencia de tropas en esos territorios aun cuando no exista otro tipo de fuentes que lo confirmen. Como bien precisa D.W. Mac Dowall, el proceso de contramarcado es similar al de reacuñado: la autoridad de la moneda anterior es reemplazada por la nueva que aclara y confirma el cambio de status '. Por ello las monedas se convierten en numerario militar, lo que conlleva que no circulen con facilidad fuera de los recintos para los que es-

* Del estudio de las contramarcas de la legio X en Hispania es responsable M.P. García-Bellido. Del estudio de la pieza contramarcada hallada en Rumania lo es E. Petac.

' D.W. Mac Dowall \& A.V.M. Hubrecht \& W.J.A. de Jong, The Roman Coins. Republic and Empire to Nerva, Description of the collections in the Provinciaal Museum G.M. Kam at Nijmegen, XII, Nijmegen 1992, 47. tán legalizadas, siendo lo habitual encontrarlas concentradas cerca de donde fueron contramarcadas, posiblemente en los mismos campamentos legionarios, en sus cannabae o vici próximos; es un hecho que las contramarcas militares se concentran en las excavaciones de campamentos o ciudades de origen campamental, siendo raro hallarlas en excavaciones de ciudades sin prehistoria militar ${ }^{2}$. La identificación de la contramarca con una legión permite pues asegurar que toda o parte de la tropa estuvo en la zona donde sus contramarcas se concentran.

Más difícil es precisar la cronología de estas contramarcas pues en la mayoría de los casos estos sellos no se hacen sobre moneda coetánea sino anterior, o muy anterior, cuando el escenario geográfico en el que ocurre no cuenta con cecas próximas que alimenten regularmente de moneda el campamento y existe una circulación arcaizante, por ello nos encontramos las mismas contramarcas en monedas muy distantes cronológicamente, siendo a veces posible que todas ellas, viejas y nuevas, fuesen contramarcadas en un sólo momento. Para ello es esencial un buen estudio del cuño del resello. Es seguro, por ejemplo, que la contramarca del águila fue utilizada durante largo tiempo y en muy diferentes zonas hispánicas dada la variedad de formas y punzones que poseemos.

El estudio más completo sobre el tema de los resellos se ha hecho para oriente, al estudiar las contramarcas monetales en moneda imperial griega. Allí se han podido detectar las variadas formas de contramarcar moneda que usa por ejemplo la legión $X$ Fretensis, los ámbitos que ocupa y posiblemente las diferentes vexillationes que están en campaña con tipos diferentes de punzón para trasmitir el mismo mensaje: la propiedad de la legio X Fretensis sobre esas monedas ${ }^{3}$.

${ }^{2}$ Cf. v.g. M. Gechter: Die Anfänge der Niedergermanischen Limes, BJh 179, 1979, esp. 71-114; S. von Schnurbein, Untersuchungen zur Geschichte der römischen Militärlager an der Lippe, BerRGK 62, 1981, 5-101.

${ }^{3}$ C.J. Howgego: Greek Imperial countermarks, London 1985, esp. 17-24 
El número de contramarcas en relación con la vida campamental es muy alto como muestran los estudios de las excavaciones en Vindonisa, Novaesium, Dangstetten, etc., y sin embargo es muy bajo el que hasta hoy hemos podido identificar y asociar con seguridad a los distintos cuerpos legionarios. En los campamentos del limes germánico las contramarcas se concentran por áreas, asociándose sin duda a las distintas legiones o campamentos uniy bilegionarios allí establecidos, pero no hemos podido todavía adjudicarlas a legiones precisas por nuestra ignorancia del emplazamiento de éstas en fechas augústeas tempranas ${ }^{4}$. Los ocupantes de la mayoría de estos campamentos son todavía anónimos por lo que sería de inmenso interés poder adjudicar ciertas contramarcas a cuerpos legionarios específicos.

En occidente sólo se ha podido identificar las contramarcas de las legiones VI (L.VI) en Hispania y la X Gémina en Hispania ( $\underline{\bar{X}}$, GEM, L.X.) y en Pannonia $(\overline{\mathrm{X}})^{5}$. En oriente la legión III Cyrenaica (LIIIC), legió VI Ferrata ( $\overline{\mathrm{VI}} \mathrm{F})$, legión X Fretensis en muy diferentes versiones (X, $\mathrm{X}, \underline{\bar{X}}, \mathrm{XF}$ y LXF) la legión XII Fulminata en diferentes formas (FVLM, L.XII, XII, LXIIF) y la XV Apollinaris (LXV, XV, XVA) ${ }^{6}$. Pero a ellas hay que añadir otras como la muy conocida de cabeza de águila en España, que siempre se asoció con la legión pero sin especificar cuerpo, $\mathrm{y}$ otras de la legión $\mathrm{X}$ que han aparecido, o hemos identificado, recientemente. A estas últimas vamos a referirnos aquí.

\section{CONTRAMARCAS Y RESELLOS DE LA LEGIO X EN HISPANIA}

Sobre las contramarcas de la Legio X Gemina o Gemella el primero que llamó la atención fue D.W. Mac Dowall al estudiar el resello X, ordinal, en monedas de Nerón aparecidas en su mayoría en la zona pannónica (fig. 1) ${ }^{7}$. La estancia de la legión en esa zona solamente entre el 62 y el 69 permitía precisar muy bien el período del contramarcado. Sin embargo la carencia de letras (L) que especificase el n. 2 .

${ }^{4}$ Por ejemplo la rueda de cuatro radios o la marca val $\mathrm{Cf}$.

5 A. de Guadán: Sobre una contramarca inédita de la Legio VI en un sestercio de Claudio, Numisma 32, 1958, 13-19 y para la X cf. M.P. García-Bellido \& C. Blázquez: Las monedas celtibéricas y sus contramarcas en el Instituto Valencia de Don Juan, AcNum. 17-18, 1987-88, 70. Cf. infra el estudio más detallado de la legión X.

${ }^{6}$ Howgego, cit. (n. 3) núms. 725-741.

7 D.W. Mac Dowall: Two Roman Countermarks of A.D. 68, NumChr. 1960, 103-112.


Fig. 1.-Sestercio de Nerón con la contramarca $X$ de la legio X Gemina (D.W. Mac Dowall).

carácter legionario de ese numeral ha sido hasta hoy el inconveniente mayor para la fiabilidad de tal lectura, pues conocíamos contramarcas de la legio VI - L. VI- pero con la «L» indicativa de l(egio) y todavía no conocíamos ninguna que recogiera sólo el nombre de la legión: Macedonica, Gemina, etc. La confirmación de que las legiones firmaban también sin «L» ha venido de occidente por un lado, los lingotes de plomo hispánico que comentaremos infra, y de oriente por otro, de la otra mitad de la misma legión, la posible gemela de la Gémina, la Legio $X$ Fretensis. Esta legión contramarca abundantemente moneda como hemos visto, no sólo $\mathrm{X}, \overline{\mathrm{X}}, \underline{\bar{X}}$ sino con L.X. o L.X.F o L.F., verificando la homologación de esas contramarcas y la fiabilidad de la interpretación de Mac Dowall para Pannonia, que había sido replicada arguyendo que las contramarcas de Pannonia en realidad eran de la XI Claudia Pia al interpretar el trazo horizontal superior de numeral ordinal como el numeral I que se uniría al X -XIhaciendo girar el resello $90^{\circ}{ }^{8}$. En Judea vemos que la $\overline{\mathrm{X}}$ utiliza también el trazo horizontal para dar carácter de numeral ordinal a la letra $\mathrm{X}$ (fig. 2). Los
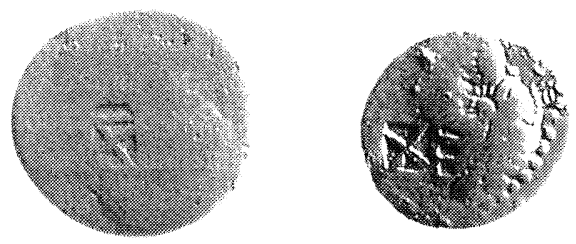

Fig. 2.-Anversos de bronces contramarcados $-\overline{\mathrm{X}}$ y $\mathrm{XF}-$ en Judea en época de Vespasiano por la legio $X$ Fretensis (C.J. Howgego).

testimonios hispánicos vienen también a apoyar la interpretación de Mac Dowall, entre otras cosas por la posición del resello en el cuello del emperador que $\sin$ embargo Kos y Semrov interpretan como

${ }^{8}$ P. Kos \& A. Semrov: Roman Imperial Coins and Countermarks of the Ist. Century (Augustus-Traianus), Luibliana 1995, 61-62. 
una damnatio memoriae de Nerón. El cuello del emperador es el lugar paradigmático en Hispania para marcar el sello legionario de la cabeza de águila (fig. 3), en tantas y tantas monedas de cecas del



Fig. 3.-Anv. de as augústeo de Celsa (Velilla del Ebro) contramarcado en el cuello del emperador con cabeza de águila. Col. IVDJ, 8'26 g.

valle del Ebro halladas en su mayoría en cuadrante nord-occidental peninsular, allí donde más legiones hubo concentradas. Precisamente la propia legio $X$ Gemina está utilizando esa misma contramarca y ese mismo lugar para estampar el resello cabeza de águila y L.X. (fig. 4).

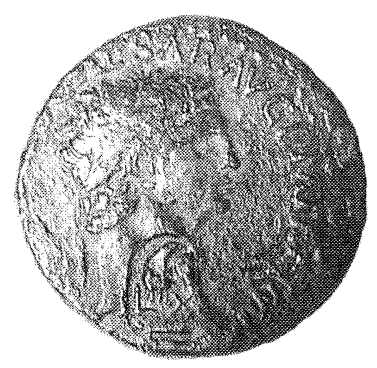

Fig. 4.-Anv. de sestercio de Claudio posiblemente de ceca hispánica. Cabeza de águila y L.X (legio $X)$ en una sola contramarca. (S. Carretero \& M.V. Romero).

Se trata de una nueva e importantísima confirmación procedente del propio campamento de la Legio $X$ Gemina en Hispania, Petavonium (Rosinos de Vidriales, Zamora). Una sola contramarca reúne pues la cabeza de águila y la denominación numeral de la legión, obligando a que nos preguntemos si en los otros casos en que aparece sólo la contramarca de cabeza de águila debemos adjudicársela también a la legión décima, interpretación que estudiamos en otro lugar ${ }^{9}$.

Vemos pues que las contramarcas de la legión $\mathrm{X}$ Gémina podían confirmarse hasta hoy a partir del período de Nerón y en dos formas - L.X y X-, las mismas que utiliza su posible gemela, la Fretensis, en Judea en época flavia, es decir, sólo unos años

\footnotetext{
${ }^{9}$ M.P. García-Bellido: Los resellos militares monetales como indicio de identidad de tropas y de sus traslados a otras provincias, II EPNA, e.p.
}

más tardías a las contramarcas pannónicas fechadas con seguridad ante quem 69 en que la legión vuelve a Hispania, fecha en que pudo efectuarse la contramarca de Petavonium. Pero hoy poseemos datos de estos mismos resellos legionarios para fechas mucho más tempranas como vemos a continuación.

\section{Los lingotes hispánicos hallados en Comacchio, Ferrara (19 a.d.C.)}

En 1980 se encontró un importantísimo pecio romano en el canal di Valle Ponti (Comacchio, Ferrara). La procedencia de la travesía fue muy discutida por la variedad de los materiales cerámicos y por la dificultad de adscribir a un territorio seguro lo que debió constituir el cargamento mayor y posiblemente el motivo del viaje: los 102 lingotes de plomo con diez sellos diferentes, uno de los cuales pertenecía claramente a Vipsanius Agrippa (fig. 5). La presencia de estos lingotes hizo que se pensase en Hispania como posible punto de partida, propuesta que hoy parece ser fidedigna si la nueva interpretación de los sellos epigráficos que propongo es correcta ${ }^{10}$.

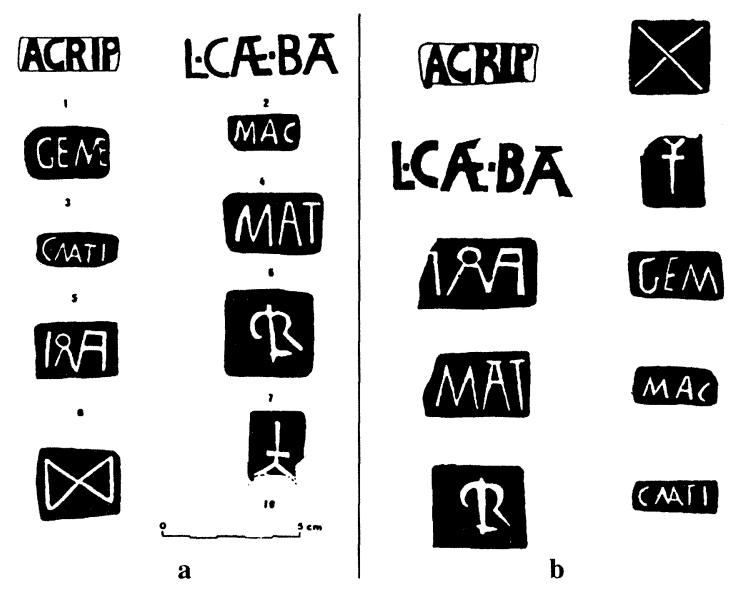

Fig. 5.-Transcripción de los sellos de los lingotes hispánicos del pecio de Comacchio, Ferrara (a- Cl. Domergue y b- F. Berti).

${ }^{10}$ Fede Berti (a cura di), Fortuna Maris. La nave romana di Comacchio, 1990. F. Berti: La nave romana di Valle di Ponti, R.St.Lig. 51, 1985, 553-570, defendiendo el origen hispánico. Como procedentes de Cerdeña, Gallia o Africa: $\mathrm{Cl}$. Domergue: Les lingots de plomb de l'épave romaine de Valle di Ponti (Comacchio), Epigraphica 49 (1987) 109-169. Ambos fechan el pecio ante quem -12 , año en que muere Agrippa. M.P. García-Bellido: Sellos legionarios en los lingotes de plomo de Comacchio (Ferrara), Epigraphica 1997, e.p.; ead. Legionsstempel aus der Zeit des Agrippa auf Hispanischen Bleibarren aus Comacchio (Ferrara), Bonner Jahrb. 1998, e.p. Cf. n. 12. 


\begin{tabular}{|c|c|}
\hline $\begin{array}{l}\text { Grandes } e \text { incusos }{ }^{11} \\
\left.1^{\circ}\right) \text { AGRIP }=\text { AGRIPPA } \\
\left.2^{\circ}\right) \text { L.CAE.BAT }=\text { L(UCIUS) CAE(SIUS) BATIUS } \\
\because \\
\text { Pequeños en relieve } \\
\left.3^{\circ}\right) \text { GEME }=\text { GEMELLA = GEMINA } \\
\left.4^{\circ}\right) \text { MAC }=\text { MACEDONICA } \\
\left.5^{\circ}\right) \text { C. MATI }=\text { C.MATIUS } \\
\left.6^{\circ}\right) \text { MAT }=\text { MATIUS }\end{array}$ & \begin{tabular}{cl} 
& \multicolumn{1}{c}{ Monogramas } \\
$\left.7^{\circ}\right)$ & LPRI $=\mathrm{L}($ egio)PRI(MA) \\
$\left.8^{\circ}\right)$ & I PRIMA $?=($ Legio PRIMA) \\
& \\
& Símbolos sueltos \\
$\left.9^{\circ}\right)$ & $\overline{\mathrm{X}}=$ diez \\
$10)$ & caduceo en cartucho
\end{tabular} \\
\hline
\end{tabular}

Creo que sólo hay tres nombres personales —núms. 1,2,5,6-, el resto son los núméros, monogramas y nombres de las legiones - MACEDONICA, $\mathrm{x}$ GEMELLA y LEGIO PRIMA- que están acantonadas con Agripa en el año 19 a.C. en Hispania con motivo del final de las guerras cántabras. Estos lingotes son testimonio de una explotación a destajo que incluye seis destacamentos legionarios, pues la Gemella y la Prima trabajan divididas a su vez en dos grupos con sellos diferentes. A ellas se suma la presencia de $L$. Caesius Batius - un lusitano a juzgar por su cognomen-, descendiente posiblemente de la clientela de L. Caesius, el pretor que firma la deditio de Alcántara del 104 a.C. Este personaje y la abundancia en esta misma zona del nombre Matius, el otro individuo constatado en los lingotes, hace suponer que fue en el SO peninsular, donde hay constatación de abundantes explotaciones de plomo argentífero y de torres-recintos de carácter minero-militar, donde tuvo lugar la concentración de estos destacamentos para la explotación del mineral. La presencia de Agrippa, tan ligado a Emerita, viene a reforzar la suposición. La fecha sería el 19 a.C. en que Agripa viene a Hispania, año y lugar en que despoja a la legio prima Augusta de su título Augusta según nos cuenta Dio Cassio 54,11. La legión no es disuelta sino degradada como supuso R. Syme, y en esta situación la vemos sellando sus lingotes con el monograma - LPRI-, sin epíteto como el de sus compañeras. Respecto a la X Gemella o Gemina utiliza sobre todo el cognomen como hace también la $\mathrm{Ma}$ cedonica, pero en casos, y posiblemente para distinguir dos diferentes destacamentos, hace uso del numeral $\underline{\bar{X}}$ con dos trazos horizontales (fig. 6) ${ }^{12}$.

$"$ La lectura de Domergue cit. (n. 10): 1) Agrippa; 2) L Caecilius Bat.; 3) Gemellus, Gemellinus, etc.; 4) Macer, Macrinus, etc.; 5+6) C. Matius; 7) Plri; 8) Ira; 9) mil, 10) caduceo. Berti, cit. (n. 10) 75, interpreta correctamente los núms. 1 y 2 como de los responsables de la explotación, 3 y 4 como siglas de compañías m(etalla) y el 9 como el numeral X.

${ }^{12}$ Cf. para la justificación de todo ello M. P. García-Bellido: opp.citt (n. 10) y ead. Las torres-recinto y la explotación militar del plomo en Extremadura: los lingotes del pecio de Comacchio, Anas 7-8, 1994-95 (1998), 187-218.



Fig. 6.-Lingote de Comacchio con la marca $\underline{\bar{x}}$ de la legio X Gemina. Fotografía cortesía de $\mathrm{Cl}$. Domergue.

\section{Contramarcas monetales en Hispania (¿época augústea?)}

Pues bien, el sello $\underline{\bar{X}}$, referente sin duda en el contexto de los lingotes de Comacchio a la legión X Gémina, es similar al utilizado por la misma legión en Pannonia y en Moesia o Rin, motivo en parte de estas notas, y por su legión gemela, la Fretensis, en Judea; pero antes las hallamos en Hispania.

Las contramarcas hispanas las encontramos sobre monedas de dos zonas peninsulares: las de Cástulo y Málaca y las del Valle del Ebro, indicando sin duda una doble presencia de la legión. Todos ellos son resellos de una misma paleografía, un $\underline{\bar{X}}$ con dos trazos horizontales, uno de ellos mayor que el otro, e inserto en un círculo (fig. 7). Estos resellos aparecen en moneda bética sobre piezas viejas, republicanas, sólo de Cástulo y Málaca, el circulante habitual en una zona muy concreta entre ambas cecas, en el camino entre ellas ${ }^{13}$. Las monedas estaban ya muy desgastadas cuando se puso la contra-

13 En Málaca en las series 2, 3 y 4, esta última fechable ante quem 91 a.C., cf. M. Campo \& B. Mora: Las monedas de Malaca, Museo Casa de la Moneda, Madrid 1995, 149 y $187 \mathrm{~s}$. Las de Cástulo sobre moneda fechable entre c. 165 y el 80, cf. M.P. García-Bellido: Las monedas de Cástulo con escritura indígena. Historia Numismática de una ciudad minera, Barcelona 1982, series 5 y 6b, pp. 203 y 210 . 



Fig. 7.-As de Málaca republicano contramarcado con $\underline{\bar{X}}$ por la legio X Gemina. Col. IVDJ, 10’27 g.

marca, de manera que ésta resalta por su nitidez sobre superficies muy lisas sin relieve ajeno que la enmascare. Parece pues que la contramarca es muy posterior a la acuñación, posiblemente estampada en época augústea. No es de extrañar que no se produjera sobre monedas de Augusto pues en esa zona -entre Cástulo y Málaca - no hubo cecas augústeas, siendo las más cercanas Acci y Colonia Patricia, ambas excesivamente lejanas y escasas de numerario para entrar en ese circuito local. Estas contramarcas las presentamos ya como sellos de la legión C. Blázquez y yo misma en 1988 sin contar entonces con el testimonio de Comacchio ${ }^{14}$. Creíamos entonces que la única justificación de la estancia de la legión en el sur peninsular podía estar en los datos de Tácito (Hist. 2,58) que la sitúa en el 69 en la boca del Estrecho de Gibraltar preparada para contraatacar en Mauritania a Albinus si éste intentaba pasar a Hispania. Hoy, con los datos del pecio de Comacchio que muestran la gran movilidad de las legiones divididas en destacamentos y formando vexillationes con otros grupos legionarios, creo que las contramarcas sobre las monedas de Cástulo y Málaca podrían estar en relación con una explotación minera en la zona geográfica entre estas dos ciudades. No es necesario insistir sobre la riqueza minera de la región de Cástulo, precisamente plomo argentífero, pero sí sobre el valor de Málaga como puerto de exportación del mineral de Cástulo, vía comercial que J. Fortea y J. Bernier ya pusieron en relación con las torres-recinto precisamente de la zona de Baena, donde muy bien pudieron efectuarse estas contramarcas ${ }^{15}$.

Estas mismas contramarcas las hallamos en moneda augústea del Valle del Ebro. Se trata de dos monedas de Celsa: la una con leyenda kelse (CNH $223,16)$ última serie ibérica fechable en época sertoriana y la otra, del XII consulado de Augusto (RPC 278), fechable en el 5-3 a.C. Otra pieza de

14 García-Bellido \& Blázquez, cit. (n. 5) 73.

15 J. Fortea y J. Bernier, Recintos y Fortificaciones ibéricos en la Bética, Salamanca 1970, 133-136. Cf. García-Bellido, cit. (n. 12).
Calagurris (RPC 445) de Augusto con título Pater Patriae (fig. 8), es fechable post 2 a.C. y la contramarca presenta el mismo desgaste que la moneda ${ }^{16}$. Las tres tienen el mismo tipo de resello, $\underline{\bar{X}}$ con dos trazos horizontales exactos a los de Comacchio inserto en un punzón circular. Las fechas pues, posiblemente de todas ellas, no han de sobrepasar los años augústeos, las del Valle del Ebro sobre moneda contemporánea al resello y las de Cástulo y Málaca en moneda vieja dada la escasez de numerario augústeo en la zona.

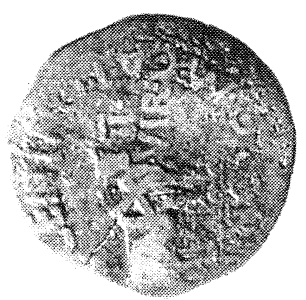

Fig. 8.-As augústeo de Calagurris contramarcado con $\underline{X}$ por la legio X Gemina. Col IVDJ, 10'79, g.

Hasta ayer no se conocía este resello sino en moneda de Cástulo y Málaca y los numismátas lo habían leido como una ko ibérica, marca de valor que aparece en una de las series de Cástulo ${ }^{17}$, pero su identidad con las otras marcas de la misma legión en zonas tan distantes del Imperio hace muy verosímil que sean nuevos ejemplares de las diferentes contramarcas de la legión $\mathrm{X}$, esta vez en Hispania y contemporáneos de los lingotes de Comacchio.

Existe otro ejemplar, también inédito, que presenta una contramarca semejante (fig. 9). Se trata de un as de Tiberio de Abdera con un resello cuadrangular dentro del cual hay una $\mathrm{X}$ asimétrica, con la base menor que la parte superior y en los laterales dos puntos, de tipología totalmente desconocida. No está recogido por Guadán y podría ser una nueva marca de la $\mathrm{X}$, esta vez en ocasión de su estancia en el sur en el año 69, según las palabras de Tácito (Hist. 2,58) que comentábamos más arriba. La contramarca no tiene sin embargo paralelo exacto, ni siquiera en los contemporáneos de Petavonium, Moesia o Pannonia y habremos de esperar a nuevos documentos para poder asociarla con mayor certidumbre a la legión X Gémina.

16 García-Bellido \& Blázquez, cit. (n. 5), Calagurris, pp. 63 y 65 . No recogíamos allí las de Celsa.

17 A. de Guadán: Tipología de las contramarcas en la numismática ibero-romana, NumHisp.t. 9, nº17, 1960: Cástulo tipo 45 , p. 39 , Málaca tipo 119 , p. $84-85$. 

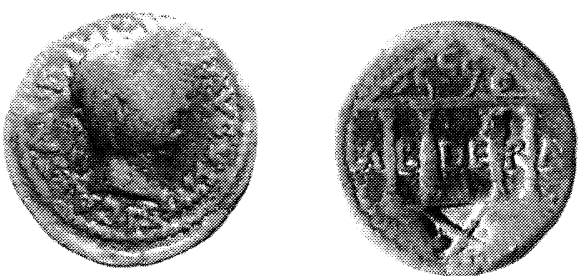

Fig. 9.- As tiberiano de Abdera contramarcado con X. IVDJ, 12'31 g.

\section{La moneda contramarcada hallada en Petavonium} (época neroniana?)

Hoy tenemos otra contramarca que viene a confirmar la calificación de legionaria que hemos adjudicado a esta contramarca X. Se trata de un sestercio de Claudio del tipo Spes Augusta (fig. 4), con una contramarca de águila en el cuello del emperador - su lugar habitual-. La pieza fue hallada en las excavaciones del propio Petavonium (Rosinos de Vidriales, Zamora) en niveles arqueológicos correspondientes a la estancia del ala II Flavia. Lo novedoso es que, formando parte de la misma contramarca, se encuentran en el cuello del águila las letras L.X., interpretadas ya por los editores como las siglas de la legio $X^{18}$. Esta moneda de Claudio - teóricamente acuñada entre el 41 y el 50 -, podría ser producto de una ceca occidental al no incluir el título de $p$ (ater) $p$ (atriae), quizás de la propia Hispania, pero sabemos que Nerón durante sus diez primeros años de reinado no acuñó moneda de bronce de manera que puede haber sido emitida entre el 41 y el $64{ }^{19}$. La pieza pudo ser contramarcada por la legión antes de salir hacia Pannonia en el 62, o mejor a su vuelta en el 68-69 en que no permanece en la Península sino un año, precisamente durante las guerras civiles en Hispania, fecha esta última muy probable para el contramarcado por varias razones: la moneda se ha hallado en los niveles del ala II flavia y su conservación es excelente, de manera que la contramarca debió ser estampada en el 69-70, justo antes de la partida de la legión hacia Arenacum y Nimega. Como vemos las fechas serían muy

${ }^{18}$ S.Carretero y M.V. Romero: Los campamentos romanos de Petavonium (Rosinos de Vidriales, Zamora), Fundación Rei Afonso Enriques, s/l, s/a, p. 10, fig. 8. La moneda ha sido publicada de momento sin peso y sin reproducción del anverso pero es posible que se trate de $\mathrm{RICI}^{2}$, Claudius $\mathrm{n}^{\circ}$ 99 , p.128, lám. 16, 99. Es una emision frecuentemente imitada por cecas occidentales y con distintas contramarcas imperiales, cf. ibm. n. 99

19 Mac Dowall, cit. (n. 1), 21; M. García de Figuerola y E. González proponen el año 69-70 en: Las contramaracas de la Legio VI en Hispania, Lancia 3, 1998, e.p. Agradezco a los AA. el haberme propocionado su trabajo antes de la publicación. homogéneas con las de los otros resellos pannónicos según cree Mac Dowall, y con los moésicos o del Rin según opina Petac, precisamente el año de la guerra civil que debió producir un alto número de moneda contramarcada para regalo a la tropa.

\section{MONEDA CON RESELLOS DE LAS LEGIONES VIII Y X HALLADA EN RUMANIA}

La moneda que presento aquí fue descubierta en Resca, Dobrosloveni (Oltenia), en la antigua Romula, capital de la Dacia Inferior (Malvensis), y pertenece a la colección numismática del instituto arqueológico Vasile Parvan de Bucarest ${ }^{20}$. Fue hallada en 1983 por Maria Rau de Resca en un lugar llamado Dealul Moril (Mill Hill) y comprada por Mihaela Blasko, quien la regaló al instituto arqueológico de Bucarest:

As de Augusto ilegible, de 7’02 g y 23 mm. (fig. 10) Anv.: tres contramarcas: AVG, VIII y $\mathrm{x}$.

Rev.: contramarca ilegible.

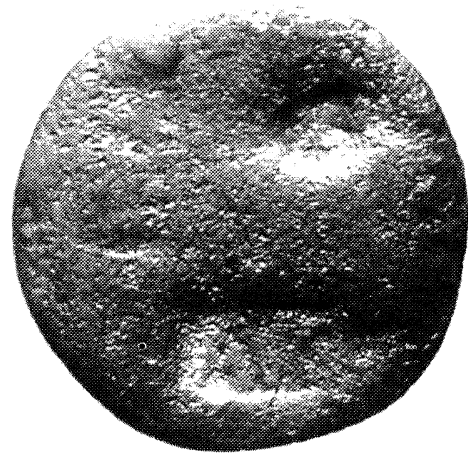

Fig. 10.-Anv. de as augústeo contramarcado (AVG, VII, $\mathrm{x}$ ) en Moesia o limes del Rin, hallado en Rumanía. Esc. 2:1.

Aunque muy mal conservado, nuestro as pertenece probablemente a las emisiones de magistrados augústeos acuñadas durante el Principado. La moneda presenta cuatro contramarcas regulares, tres de ellas (AVG, VIII y x) aplicadas en anverso y la cuarta (desgraciadamente ilegible) en el reverso. La primera de ellas es claramente más antigua que las otras ${ }^{21}$. Aparece sobre todo en ases emitidos en Roma durante el reinado de Augusto y en las series del «Altar» de

${ }^{20}$ Quiero expresar mi agradecimiento y consideración a los Profs. Drs. Gh. Poenaru Bordea y Eugen Nicolae, quienes posibilitaron el estudio y la publicación de esta moneda.

${ }_{21}$ D.W. Mac Dowall: An early imperial countermark from Pannonia, NumChr. 1966, 128-130; J.B. Giard: Catalogue des monnaies de l'Émpire Romain. I Augustus. Bibliothéque National. Paris 1976, 33-34; C.J. Howgego, cit. (n.3) p. $219, n^{\circ} 577$. 
Lugdunum, pero también en monedas del séptimo imperio de Tiberio ${ }^{22}$ y sobre monedas de oricalco acuñadas en época de Augusto ${ }^{23}$. Aunque parece haber sido usada especialmente en el área del limes del Rin ${ }^{24}$ no está excluida la posibilidad de su utilización también en los distritos surdanubianos, Tracia o Moesia ${ }^{25}$, siendo contemporánea con la pannonica (?) AVG y teniendo un terminus post quem del mes de julio del año 13 d.C. ${ }^{26}$ Muy significativo es que la presencia de esta contramarca sea posterior a los años 11-12 d.C., periodo que no presenta ningún ejemplo de ella ${ }^{27}$. La circunstancia parece estar relacionada con la importante reforma metrológica del bronce romano: la adopción de un nuevo patrón de $11 \mathrm{~g}$ para los ases ${ }^{28}$. Siguiendo el mismo razonamiento para las emisiones de oricalco, Tiberio introdujo un nuevo patrón metrológico para los dupondios (piezas más pesadas de 14-15 g, en lugar de los 1213) ${ }^{29}$. El peso de las monedas contramarcadas con AG O AVG confirma esta situación, incluso teniendo los dupondios contramarcados pesos inferiores al patrón tiberiano para los medios bronces ${ }^{30}$. Por lo tanto la primera contramarca aplicada a nuestra moneda le da el valor de as tiberiano ${ }^{31}$.

Respecto a las otras dos contramarcas, vIII y $\mathrm{x}$, pertenecen a las legiones VIII Augusta y muy probablemente a la X Gemina ${ }^{32}$. La posibilidad de que la última perteneciera a la $X$ Fretensis ${ }^{33}$ es muy escasa puesto que esta unidad estuvo durante los dos primeros siglos de la era acuartelada casi exclusivamente en Judea ${ }^{34}$. El único momento en el que algunas vexillationes de la legión Fretensis vinieron a Europa está relacionado con la misión de Mucianus en el año de los cuatro emperadores ${ }^{35}$. No tenemos ninguna constatación de la presencia de alguna vexillatio de la legio $X$ Fretensis en Europa junto a la legio vIII Augusta; sólo existen informaciones sobre

\footnotetext{
${ }_{22}$ Mac Dowall, cit. (n. 21) 128.

23 Ibm. 129

${ }^{24}$ Ibm. 128

${ }^{25}$ Giard, cit. (n. 21) 33-34; Howgego cit. (n. 3) 219, n577

26 Mac Dowall, cit. (n. 21) 128

27 Ibm. 127

28 Ibm.; Giard, cit. (n. 21) 8.

29 Mac Dowall cit. (n. 21) 127.

30 Ibm. 128.

Ibm. 130

32 Para las contramarcas de la legio X Gémina cf. D.W. Mac Dowall, cit. (n.7) 103-112 y supra.

${ }^{33}$ Para el miso tipo de contramarca pero de la legio X Fre tensis cf. Howgego cit. (n. 3) $252, \mathrm{n}^{\circ} 729$ ii y 254 , núms 734-735.

34 H.M. Parker: The Roman Legions, Oxford 1928, 119 , $140,145,158$ y 163

35 Tácito (Hist. 2, 23 y 3, 46), cf. también Dio Cassio $(54,9)$ donde no existe una clara referencia a la presencia de unidades de Judea en el ejército de Mucianus; cf. Parker, cit. (n. 34) 142 .
}

la llegada de Mucianus a Europa con la legio vi Ferrata y otros 13.000 soldados de Siria y Judea, estacionándose en Moesia, donde también estaba la viII Augusta ${ }^{36}$. Debemos por tanto considerar, sólo desde un punto de vista teórico, una eventual aunque poco probable aplicación de las dos contramarcas - VIII y X- en Moesia en el año $69^{37}$.

La contramarca $X$ representa sin embargo una variante de la contramarca panónica $\overline{\mathrm{X}}$ publicada por MacDowald hace más de treinta años ${ }^{38}$. Es conocida sólo en trece ejemplares (once en colecciones centroeuropeas y dos en los museos occidentales de París y Copenhague), todas ellas sobre bronces neronianos y la contramarca pertenece al periodo de la guerra civil ${ }^{39}$.

En el anverso de nuestra moneda hay una tercera contramarca, VIII, perteneciente a la legio VIII Augusta. Siguiendo la opinión de C.J. Howgego a propósito de la presencia de dos contramarcas legionarias sobre una misma moneda ${ }^{40}$, se supone que la única oportunidad en la que nuestra moneda pudo sufrir ambos contramarcados está en conexión con los sucesos del año 70 d.C., el año de la expedición de Cerealis contra Civilis jefe de los Batavos ${ }^{41}$, campaña en la que Roma puso en acción no menos de nueve legiones y entre ellas la legio viII Augusta y la legio X Gemina ${ }^{42}$.

Podemos pues concluir que nuestra moneda estaba todavía en el circuito monetario imperial en el área moesica, o mejor en el del limes del Rin, en un momento cuyo termino post quem está fijado por la guerra civil en los años 69-70 d.C. De la zona del hallazgo de esta moneda tenemos otras varias piezas, ninguna de ellas anterior a los comienzos del s. II ${ }^{43}$ y creemos por lo tanto que se puede defender la hipótesis de una tardía penetración de esta moneda en el área entre el Danubio, Olt y los montes Cárpatos. La moneda probablemente llegó a la capital de la Dacia inferior (Malvensis) tras la conquista del reino dacio.

\section{EPÍLOGO}

La posibilidad de precisar estancias de grupos militares en zonas que no conocíamos, gracias a las

${ }^{36}$ Parker, ibm. 142 n. 1,140

37 Howgego, cit. (n. 3) $253, n^{\circ} .729$ y $255 n^{\circ} 736$

38 Mac Dowall, cit. (n. 7) 103-112.

39 Ibm. 104

${ }^{40}$ Howgego, cit. (n.3) 253. n 729

41 Tácito, His.4, 68-70 y 5,19; Dio Cassio 66, 3; cf. también Parker cit. (n. 34) 143-144.

42 Parker, cit. (n.34) 144.

43 Poseemos seis monedas: Hadriano 1 as, Hadriano? 1 as, Antonino Pio (Faustina II) 1 as, Marco Aurelio (Faustina II) 1 dupondio, Commodo (Crispina) 1 dupondio. 
contramarcas efectuadas por ellos en moneda local, o gracias a la acumulación en esa zona de una precisa contramarca sobre moneda foránea, es de gran importancia, sobre todo para la adjudicación de legiones a los campamentos renanos. El hecho de que en muchos casos, como hemos visto, estos datos numismáticos se vean avalados por los bien conocidos y comprobados de las fuentes literarias y arqueológicas, permite aplicar el método con seguridad a aquellas etapas y regiones donde carecemos de esa otra más precisa documentación.

La identificación de los resellos sobre los lingotes de Comacchio parece localizar en la región extremeña una importante explotación legionaria del plomo, zona de donde procederían los lingotes hallados en el pecio de Comacchio. Es en estos lingotes donde por primera vez, en el año 19 a.C., constatamos sellos legionarios que se pondrán tan de moda a partir de época flavia, sobre todo en los materiales edilicios. Las contramarcas monetales hispánicas en moneda de la Bética, proporcionan igualmente información, aunque mucho menos segura, sobre la probable estancia de tropas de esta legión en esa zona. De ambas zonas bético-lusitanas procede un alto número de los soldados de la legio $\mathrm{X}$, en total 12 individuos de 18 que constatan su origo: Hasta, Hispalis, Arsa, Ugia, Emerita (3), Valentia (posiblemente la lusitana), Tucci (2), Ulia, Astigi CIM núms. 547-569 ${ }^{44}$. Estas lápidas atestiguan la presencia de la legión en esas zonas donde se haría el reclutamiento, en casos dentro de grupos familiares como demuestra la $n^{\circ} 560$ hallada en Carnuntum

${ }^{44} \mathrm{CIM}=$ Corpus de Inscripciones militares, en J.M. Roldán, Hispania y el ejército romano, Salamanca 1974, pp. 304307.
(Pannonia) donde es un hermano quien dedica el monumento al fallecido.

Del valle del Ebro, exactamente de Calagurris, proceden dos soldados que van a morir a Nimega, estancia en el NE peninsular a la que debemos adjuntar el testimonio de la construcción del puente de Martorell firmada por las legiones X Gémina, la IV Macedónica y la VI Victrix ${ }^{45}$.

A las guerras civiles podemos adjudicar las contramarcas de la legión en Panonia y en Moseia o zona renana. Posiblemente sólo meses más tarde la legión contramarcará el sestercio aparecido en Petavonium, comprobándose una acumulación de moneda contramarcada en esas fechas, muy propicias para los regalos a la tropa: Parece que no tenemos testimonios más tardíos.

Los resellos de los lingotes de Comacchio, fechables en el año 19 a.C. gracias a la firma de Agripa en ellos, constituyen pues el documento más antiguo de todas las marcas legionarias occidentales, si excluimos naturalmente los grafitos o marcas en glandes amén de las monedas legionarias habituales en la Republica tardía, cuyos mejores testimonios son las emisiones de Marco Antonio o las glandes de Q. Metellus halladas en Azuara (Badajoz) ${ }^{46}$. Los lingotes de plomo nos proporcionan además un modelo tipológico para la identificación de otras marcas o resellos de la legión, marcas que ya habían sido identificadas en otros lugares del Imperio a los que hoy hemos podido añadir más documentáción.

45 F.Fabre \& M.Mayer \& I. Rodá, Inscriptions romaines de Catalogne, I. Bercelone (sauf Barcino), Paris 1984, 36,1.

46 RRC 544, 1-39 y Cl. Domergue: Un temoignage sur l'industrie minière et metalllurgique du plomb dans la region d'Azuaga (Badajoz) pendant la guerre de Sertorius, XI CAN 1970, 608-625 